\title{
In Vitro Idiotypic Suppression of Chronic Lymphocytic Leukemia Lymphocytes Secreting Monoclonal
}

\section{Immunoglobulin M Anti-Sheep Erythrocyte Antibody}

\author{
Constantin A. Bona and Anthony S. Fauci, Laboratory of Immunology and the \\ Laboratory of Clinical Investigation, National Institute of Allergy and Infectious \\ Diseases, National Institutes of Health, Bethesda, Maryland 2020.5
}

A BSTRACT A patient with chronic lymphocytic leukemia was found to have $B$ cells with surface immunoglobulin (Ig)M manifesting anti-sheep erythrocyte (SRBC) specificity together with a high titer serum monoclonal anti-SRBC IgM antibody. By immunizing a sheep with the monoclonal IgM antibody, followed by multiple absorptions against normal human IgM, an anti-idiotype (Id) antibody was obtained. The serum IgM anti-SRBC antibody was then demonstrated to share the same idiotypic determinants with the surface IgM with anti-SRBC specificity on the patient's B cells.

The anti-Id antibody suppressed the spontaneous secretion of anti-SRBC antibody as well as the pokeweed mitogen-induced anti-SRBC antibody production as measured by a hemolysis-in-gel plaque-forming cell assay. In contrast, pokeweed mitogen-induced antiSRBC plaque-forming cell responses of normal individuals were not suppressed by the anti-Id antibody. Thus, this study demonstrates in vitro suppression of human B-cell function by anti-Id antibody.

\section{INTRODUCTION}

The association of anti-idiotypic (Id) ${ }^{1}$ antibodies with certain immunoregulatory phenomena has been clearly demonstrated in animal models. For example, idiotypespecific suppression of the growth of mouse myeloma cells can be demonstrated in mice with anti-Id antibodies (1-4). Furthermore, anti-Id antibodies are able to suppress the synthesis by normal B cells of antibodies carrying the relevant idiotypes. This suppression can be the result of either a direct effect of anti-Id antibodies on the precursors of antibody-forming cells, as

Received for publication 6 June 1979 and in revised form 30 October 1979.

${ }^{1}$ Abbreviations used in this paper: CLL, chronic lymphocytic leukemia; E, erythrocyte; Id, idiotype; Ig, immunoglobulin; PFC, plaque-forming cell; PWM, pokeweed mitogen; SRBC; sheep erythrocyte; TCE, T cell-enriched. shown in the inulin and phosphorylcholine systems $(5,6)$, or by generation of suppressor $T$ cells that can inhibit helper functions in the arsonate and streptococcal systems $(7,8)$.

In the present paper, we report studies of a patient with chronic lymphocytic leukemia (CLL) who had high titer serum monoclonal immunoglobulin (Ig)M antisheep erythrocyte (SRBC) antibody, and whose B cells expressed surface IgM with anti-SRBC specificity. An anti-Id antibody was produced by immunizing sheep with the monoclonal serum anti-SRBC antibody, followed by multiple absorptions against pooled normal serum IgM. The anti-SRBC antibody in the serum and on the surface of the patient's B cells was shown to be idiotypically identical. Furthermore, the anti-Id antibody suppressed the spontaneous secretion of anti-SRBC antibody by the leukemic B cells as well as the pokeweed mitogen (PWM)-induced anti-SRBC antibody production as measured by a hemolysis-ingel plaque-forming cell (PFC) assay.

\section{METHODS}

Patient. The patient is a 64-yr-old male who was diagnosed as having CLL. The diagnosis of CLL is based on a total leukocyte count ranging from 7,000 to 20,000 cells $/ \mathrm{mm}^{3}$ with a range of $40-90 \%$ lymphocytes. Up to $80 \%$ of the lymphocytes bear surface Ig (IgM, $\kappa$-light chain). The patient has never received therapy for his CLL.

Cell suspensions. Heparinized venous blood was obtained from the patient and from normal volunteers; mononuclear cell suspensions were obtained by standard Hypaque-Ficoll density centrifugation.

Fractionation of mononuclear cell suspensions. T cellenriched (TCE) suspensions were obtained by two separate methods. In the first method, TCE suspensions were obtained by rosetting lymphocytes with sheep erythrocytes (E), followed by centrifugation of rosetted cells over HypaqueFicoll gradients as previously described (9). The alternative method of obtaining TCE suspensions was to pass mononuclear cells over a nylon wool column.

Culture conditions. Culture conditions for the generation 
of anti-SRBC PFC after polyclonal stimulation of human blood lymphocytes with PWM were carried out according to methodologies that have been previously described in detail $(10,11)$.

Assay for PFC. Lymphocytes were assayed for direct PFC against SRBC by an ultrathin layer complement dependent hemolysis-in-gel technique as previously described in detail $(10,11)$. This was performed on cells obtained immediately after separation from blood (spontaneous PFC) and after 7 $\mathrm{d}$ in culture with or without PWM.

Preparation of anti-Id antisera. Three strain 13 guinea pigs were immunized with $100 \mu \mathrm{g}$ of the patient's monoclonal IgM anti-SRBC antibody emulsified in Freund's complete adjuvant. Starting 4 wk after immunization, the guinea pigs were bled weekly and sera were screened in an immunodiffusion assay for antibodies to IgM. Sheep 3501 (National Institutes of Health Animal Farm, Poolesville, Md.) was immunized with $3 \mathrm{ml}$ of packed autologous SRBC (3501-SRBC) coated with $100 \mu \mathrm{g}$ of the patient's monoclonal IgM anti-SRBC antibody emulsified in Freund's complete adjuvant. Adsorption of the antibody was performed by incubation of 3501-SRBC with the monoclonal IgM for $1 \mathrm{~h}$ at room temperature. After immunization, the sheep were bled weekly and precipitating antibodies were detected by immunodiffusion. Guinea pig and sheep anti-Id sera were made specific for the patient's monoclonal IgM by five adsorptions, on an immunoadsorbent prepared according to Avremeas et al. (12), from a pool of normal IgM as well as from a Waldenström's macroglobulin (kindly provided by Dr. Henry Metzger, National Institutes of Health, Bethesda, Md.).

Determination of anti-Id activity of guinea pig and sheep antisera. After five adsorptions of an immunoadsorbent prepared from normal IgM or a macroglobulin, determination of anti-Id activity was performed by two methods: (a) A hemagglutination assay in microtiter plates using horse erythrocytes coated by the chromic chloride method (13) with the patient's monoclonal IgM, the patient's IgG, and IgM from normal healthy subjects. The titers were expressed as $1 / \log _{2}$ of the highest dilution of antisera giving agglutination. $(b)$ A radioimmunoassay in microtiter plates using sheep or guinea pig anti-Id antibodies and ${ }^{125}$ I-labeled patient's monoclonal IgM.

In addition, a hemagglutination inhibition assay was used to test the ability of anti-Id antibodies to react with the combining site of monoclonal IgM as described previously (13).

Effect of anti-Id antisera on anti-SRBC PFC. To determine the effect of anti-Id antibody on spontaneous anti-SRBC PFC, freshly drawn lymphocytes from the patient and from three normal individuals were immediately placed in the PFC assay with agar into which various dilutions of the sheep and guinea pig pre- and postimmunization antisera were added. After $2 \mathrm{~h}$ of incubation guinea pig complement was added and incubation was continued for an additional hour. PFC were then counted using a dissecting microscope.

To determine the effect of anti-Id antibody on PWMinduced PFC, various dilutions of the above antisera were added on day 0 directly to lymphocyte cultures from the patient and three normal individuals in the presence and absence of PWM. PFC were counted after $6 \mathrm{~d}$ of culture. In separate experiments, to control for the carry-over of anti-Id antibody from the cultures to the assay system, cultures were done for $6 \mathrm{~d}$ in the presence of PWM, but without anti-Id antibody. At the end of the 6-d culture period, a 1:30 dilution of anti-Id was added to the cultures immediately before harvesting. The cultures were then washed three times and cells were placed in the PFC assay.

Determination of the presence of Id or anti-Id on cells. To determine the presence of Id on the B cells of the patient and normals, mononuclear cells were first incubated for $45 \mathrm{~min}$ at $37^{\circ} \mathrm{C}$ with either control media or a $1: 100$ dilution of sheep preimmunization IgG or sheep IgG anti-Id. After incubation, cells were washed and stained with fluoresceinated goat anti-human Ig (14) to determine whether the anti-Id blocked the expression of surface Ig.

To determine whether the idiotypic determinants were present on T cells, TCE suspensions were obtained from two normal individuals by the E-rosette enrichment method (9) and by the nylon wool column method, and from the patient by the nylon wool method. The E-rosette enrichment method was inadequate in obtaining purified TCE suspensions from the patient, because the patient's B cells expressed surface Ig with anti-SRBC activity and consequently bound to the SRBC to form E rosettes (15).

The sheep control and anti-Id antisera were conjugated with fluorescein isothiocyanate, and the TCE suspensions of the patient and normals were assayed for the presence of idiotypic determinants.

To determine whether anti-Id determinants were present on $T$ cells, nylon-purified TCE suspensions from the patient and two normal individuals were preincubated for $30 \mathrm{~min}$ at $37^{\circ} \mathrm{C}$ with a $1: 10$ dilution of the patient's $\operatorname{IgM}, \operatorname{IgG}$, and a normal IgM. Cells were washed and binding of the different Ig was determined by reacting the cells with fluoresceinated goat anti-human Ig.

\section{RESULTS}

Fractionation of serum on Sephadex G-200 columns. Normal serum pooled from four donors, as well as serum from the patient, were fractionated separately on Sephadex G-200 columns (Pharmacia Diagnostics, Div. of Pharmacia Inc., Piscataway, N. J.). SRBC hemagglutinins were tested on fractions that included both IgM and IgG. Anti-SRBC hemagglutination activity was found predominantly in the IgM fractions of the patient. These fractions were pooled and used to raise anti-Id sera.

Determination of anti-Id activity of guinea pig and sheep antisera. Data in Table I demonstrate that both guinea pig and sheep antisera contain anti- $\operatorname{IgM}$ antibodies but that after five adsorptions on pooled normal human IgM only anti-Id antibodies were detected. These five-times-adsorbed sera were subsequently used in the radioimmunoassay. A dose-effect relationship between the dilution of these antisera and the binding of ${ }^{125}$ I-labeled IgM (patient) was observed indicating that both guinea pig and sheep antisera contain anti-Id antibodies (Fig. 1).

Specificity of anti-Id antisera. The ability of guinea pig and sheep anti-Id antisera to react with the combining site of the patient's IgM anti-SRBC antibodies was studied in a hemagglutination inhibition assay. The data presented in Fig. 2 and Table II show that only sheep anti-Id antibody was able to inhibit the hemagglutination activity of the patient's $\operatorname{IgM}$ antiSRBC antibodies. These data suggest that anti-Id antibodies produced in sheep were combining site specific, whereas guinea pig antibodies were directed against some other antigenic determinant, probably located on the framework of the variable region of the 
TABLE I

Hemagglutination Titer $\left(\log _{2}\right)$ of Guinea Pig and Sheep Anti-idiotypic Sera

\begin{tabular}{lccccc}
\hline & & \multicolumn{4}{c}{ Horse erythrocytes coated with:* } \\
\cline { 3 - 6 } Number of & $\begin{array}{c}\text { Nongin of } \\
\text { adsorptions } \\
\text { on human } \\
\text { Ig.Mt }\end{array}$ & $\begin{array}{c}\text { Patient } \\
\text { Ig.I }\end{array}$ & $\begin{array}{c}\text { Patient } \\
\text { IgG }\end{array}$ & $\begin{array}{c}\text { Walden- } \\
\text { ström's } \\
\text { macro- } \\
\text { globulin }\end{array}$ & $\begin{array}{c}\text { Normal } \\
\text { Ig.M }\end{array}$ \\
\hline Guinea pig & 0 & $>24 \S$ & 0 & 20 & 19 \\
& 4 & 6 & 0 & 3 & 1 \\
Sheep & 5 & 4 & 0 & 0 & 0 \\
& 0 & 20 & 0 & 14 & 15 \\
& 4 & 5 & 0 & 2 & 1 \\
& 5 & 5 & 0 & 0 & 0
\end{tabular}

* Chromic chloride method was used to coat horse erythrocytes with various proteins (see Methods).

$\$ 1 \mathrm{ml}$ of ammonium sulfate-precipitated Ig fraction, prepared from Sephadex G-200-separated IgM, was adsorbed on $100 \mathrm{mg}$ of immunoadsorbent from four normal pooled serum. $\S$ Hemagglutination titer $\left(\log _{2}\right)$.

IgM anti-SRBC antibody, but apparently not related to the combining site.

Effect of anti-Id antisera on spontaneous anti-SRBC $P F C$. The effect of various dilutions of the anti-Id antisera on the spontaneous anti-SRBC PFC from the patient is shown in Fig. 3. Neither sheep nor guinea pig preimmunization sera inhibited spontaneous antiSRBC PFC at any dilution tested. However, the sheep anti-Id that is most likely specific for the antiSRBC combining site completely suppressed PFC responses at dilutions of $1: 100$ and $1: 300$, and suppressed to almost $50 \%$ of control at a dilution of $1: 1,000$. On the other hand, the guinea pig anti-Id, which, as shown in Fig. 2 and Table II, is likely specific for determinants other than the combining site of the idiotypic antibody, failed to suppress PFC responses.

Because normal individuals do not express spontaneous anti-SRBC PFC before culture with PWM, it was impossible to determine the effect of the various anti-Id antisera on unstimulated normal lymphocytes.

Effect of anti-Id antisera on PWM-induced antiSRBC PFC. The effects of various dilutions of anti-Id antisera on the PWM-induced anti-SRBC PFC of a normal individual and the patient are shown in Figs. 4 and 5, respectively. Neither preimmunization nor anti-Id antisera from sheep or guinea pig suppressed the PWM-induced PFC of the normal individual (Fig. 4). This experiment was done three times using three different normal subjects and the results were similar in each, i.e., no suppression. With the patient there was no suppression with either sheep or guinea pig preimmunization sera. However, sheep anti-Id antiserum, which blocks the combining site of the patient's monoclonal IgM anti-SRBC antibody, markedly sup-

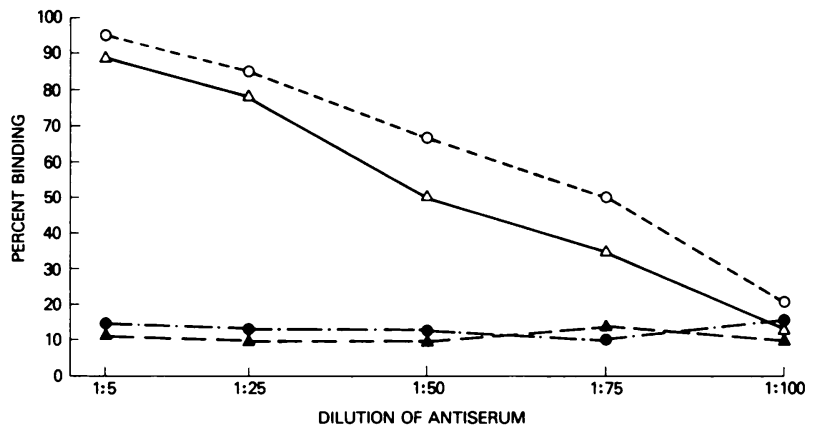

FIGURE 1 Binding of various antisera to ${ }^{125}$ I-labeled patient Ig.M. Neither sheep nor guinea pig preimmunization antisera bound to the patient's IgM. However, both sheep and guinea pig postimmunization antisera, after multiple adsorptions with pooled normal IgM and a macroglobulin from a patient with Waldenstrom's macroglobulinemia, did not bind to normal Ig.M (Table I). Hence, both sheep and guinea pig postimmunization antisera were directed against the patient's Ig.M idiotype. - sheep preimmunization; $O$, sheep anti-Id; $\boldsymbol{\Delta}$, guinea pig preimmunization; $\triangle$, guinea pig anti-Id.

pressed the PWM-induced anti-SRBC PFC at a dilution of 1:30. In addition, there was a lesser degree of, but nonetheless obvious suppression at higher dilutions (Fig. 5). On the other hand, the guinea pig anti-Id antiserum, which reacts with noncombining site determinants, did not suppress.

It was highly unlikely that the suppression seen in the PWM-stimulated cultures, which contained sheep

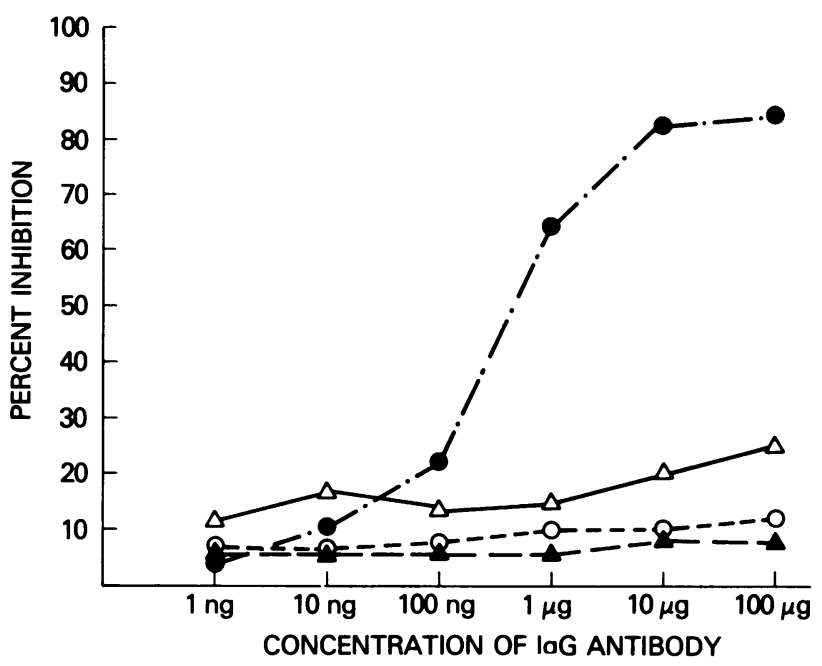

FIGURE 2 Inhibition by various antisera of the hemagglutination of SRBC by the patient's monoclonal IgM. Both the sheep antibody directed against normal IgM and the patient's IgG and guinea pig antibody directed against the patient's IgM failed to inhibit hemagglutination of SRBC by the patient's IgM. However, sheep antibody directed against the patient's IgM clearly inhibited hemagglutination in a concentrationdependent fashion. , sheep anti-IgM (patient); $\bigcirc$, sheep antiIgM (normal); $\Delta$, sheep anti-IgG (patient); $\triangle$, guinea pig anti-IgM (patient). 
TABLE II

Inhibition by Anti-idiotypic Sera of Hemagglutination of SRBC by Patient's Monoclonal IgM

\begin{tabular}{lc}
\hline \multicolumn{1}{c}{ Origin of serum } & $\begin{array}{c}\text { Hemagglutination inhibition titer } \\
\left(\log _{2}\right)\end{array}$ \\
\hline Guinea pig preimmunization & 0 \\
Guinea pig anti-Id & 0 \\
Sheep preimmunization & 0 \\
Sheep anti-Id & 6 \\
\hline
\end{tabular}

anti-Id antibody, was the result of the carry-over of the anti-Id antibody from the culture to the assay system, which then blocked not the secretion of antibody but the binding of anti-SRBC antibody to the target erythrocytes. In control experiments in which anti-Id antibody in a dilution of 1:30 was added to the cultures not at the beginning of the 6-d culture but at the termination, immediately before harvesting, no suppression of PFC responses was observed.

Determination of Id on B cells. The patient's mononuclear cells and those of two normals were incubated for $45 \mathrm{~min}$ at $37^{\circ} \mathrm{C}$ with either control media or a $1: 100$ dilution of sheep preimmunization IgG or sheep IgG anti-Id. After incubation, cells were washed and stained

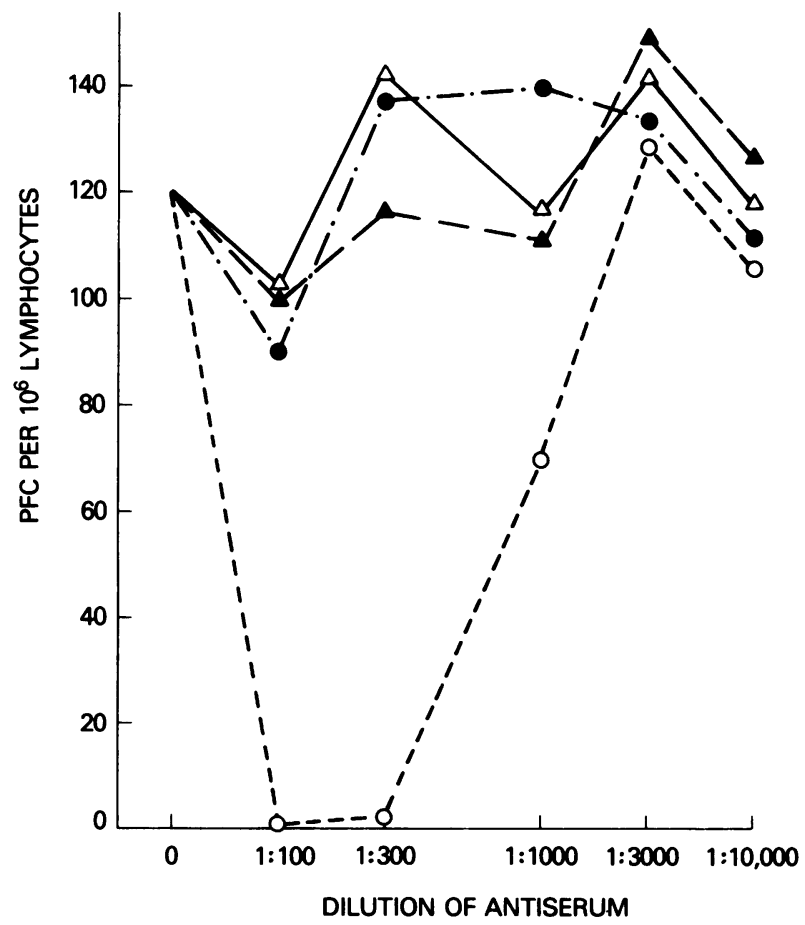

FIGURE 3 Effect of various dilutions of antisera on the spontaneous (day 0) anti-SRBC PFC response of the patient's lymphocytes. Only the sheep anti-Id suppressed spontaneous anti-SRBC PFC responses. - sheep preimmunization; $O$, sheep anti-Id; $\boldsymbol{\Delta}$, guinea pig preimmunization; $\Delta$, guinea pig anti-Id.

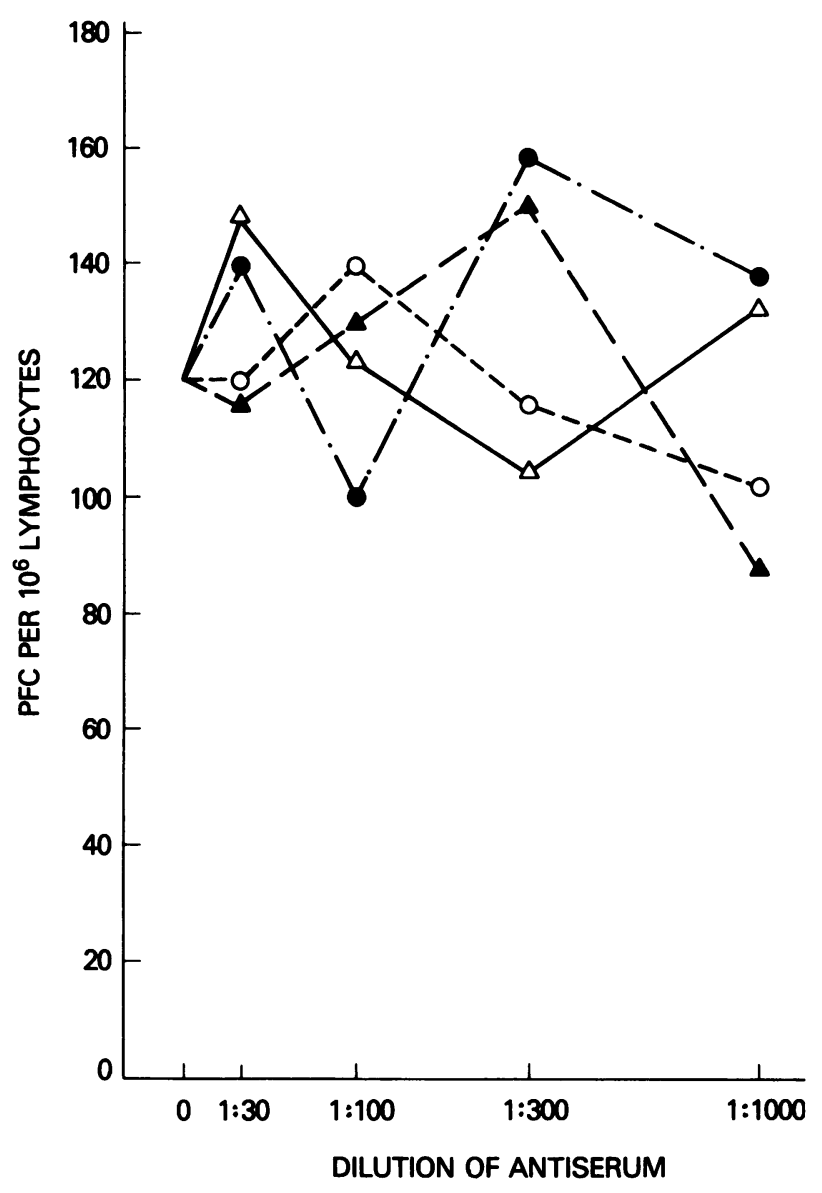

FIGURE 4 Effect of various antisera on the PWM-induced anti-SRBC PFC response of normal lymphocytes. The antisera were added to cultures on day 0 with PWM, and antiSRBC PFC responses were measured after $6 \mathrm{~d}$ of culture. Neither the pre- nor postimmunization antisera from sheep or guinea pig suppressed the anti-SRBC PFC responses. sheep preimmunization; $O$, sheep anti-Id; $\boldsymbol{\Delta}$, guinea pig preimmunization; $\triangle$, guinea pig anti-Id.

with fluoresceinated goat anti-human Ig. Preincubation with neither sheep preimmunization nor sheep IgG anti-Id blocked the subsequent staining of the normal $B$ lymphocytes with fluoresceinated goat anti-human Ig. With the patient, preincubation with sheep preimmunization IgG did not block, but sheep anti-Id completely blocked the detection of surface $\mathrm{Ig}$ by the fluoresceinated goat anti-human Ig reagent.

Presence of Id on T cells. Purified T cells from the patient and two normals were assayed for the presence of Id by staining with the fluoresceinated sheep IgG anti-Id. Id determinants were not detected on $\mathrm{T}$ cells of either the patient or the normal.

Presence of anti-Id on $T$ cells. Purified T cells from the patient and two normals were preincubated for 30 min at $37^{\circ} \mathrm{C}$ with a $1: 10$ dilution of the patient's IgM, IgG, and normal IgM. Cells were then washed and 


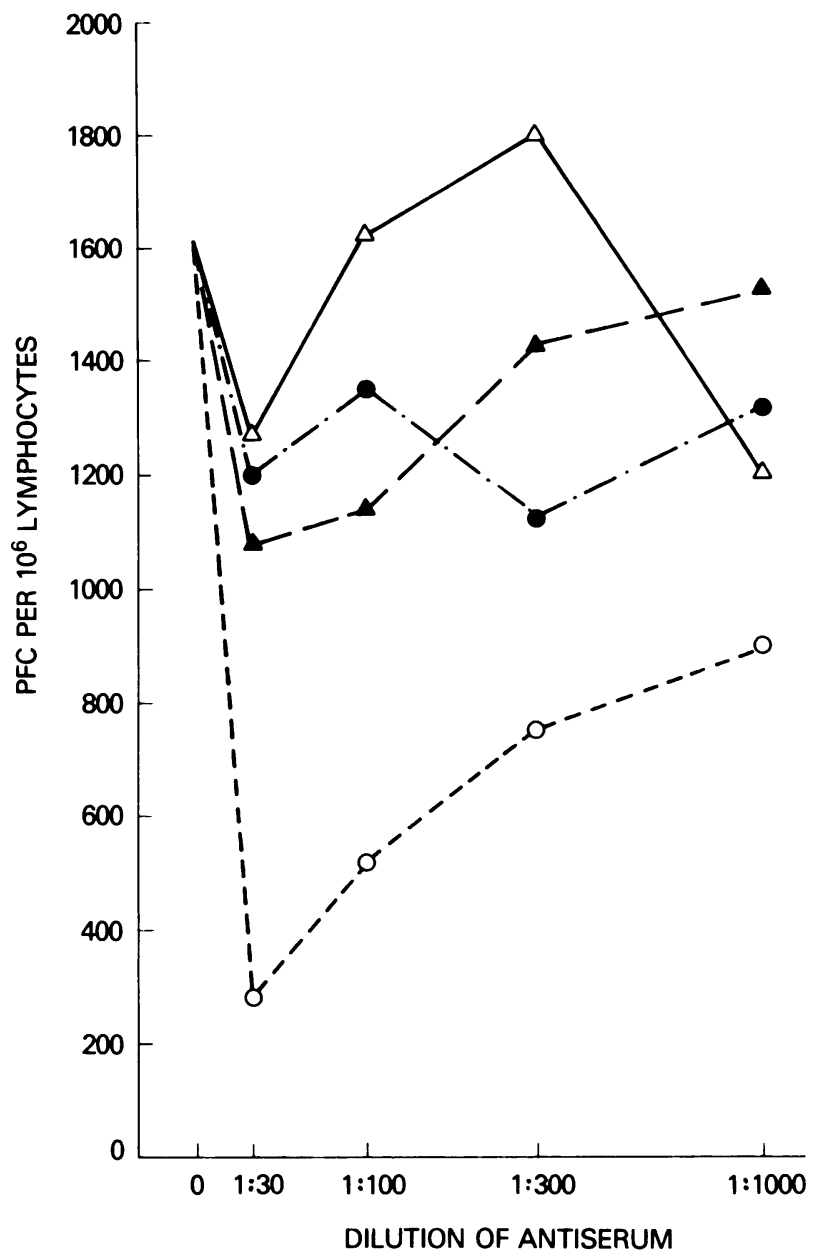

Figure 5 Effect of various antisera on the PWM-induced anti-SRBC PFC response of the patient's lymphocytes. The antisera were added to cultures on day 0 together with PWM, and anti-SRBC PFC responses were measured after $6 \mathrm{~d}$ of ('ulture. Only the sheep anti-Id antiserum suppressed the antiSRBC PFC responses. sheep preimmunization; $O$, sheep anti-Id; $\boldsymbol{\Delta}$, guinea pig preimmunization; $\triangle$, guinea pig anti-Id.

stained with fluoresceinated sheep anti-human Ig. No staining was observed with patient or normal T cells. Hence, anti-Id was not detectable on the patient's $\mathrm{T}$ cells.

\section{DISCUSSION}

Most patients with CLL manifest a monoclonal proliferation of B cells $(16,17)$. Although surface Ig can be demonstrated on the surface of a major portion of the leukemic lymphocytes in patients with CI.L, there is frequently a defect in the ability of these cells to terminally differentiate into Ig-secreting cells (16-18). However, the maturational defect is variable among patients in that leukemic B cells from certain CLL patients have been demonstrated to synthesize and secrete Ig (19). In fact, in line with the monoclonal nature of the B-cell proliferation, a recent study has elegantly described a patient with CLL in whom the Ig.M on the surface membrane of the lymphocytes, the intracellular Ig.M in the differentiated plasma cells, and the monoclonal Ig.I in the serum were shown to be idiotypically identical (20).

The CLL patient reported in the present study provided a unique opportunity to examine the effect of anti-Id antisera on the regulation of human B-cell function. The two features that allowed this approach were that the CLL lymphocytes were capable of secreting Ig.M, and the Ig.M in the serum was idiotypically identical to the surface IgM on the leukemic $\mathrm{B}$ cells. More importantly, the B cell surface $\mathrm{IgM}$ and the serum Ig.M had specificity for SRBC, making the spontaneous and mitogen-induced IgM secretion easily detectable at the single cell level by an hemolysis-ingel anti-SRBC PFC assay (10, 11). A CLL patient whose leukemic B cells expressed surface Ig that reacted with SRBC to form rosettes has been previously reported (21). However, Ig secretion was not determined. In the present study, not only did the patient's leukemic B cells spontaneously secrete anti-SRBC antibody, but they could also be induced by PWM to differentiate further in culture to secrete the SRBC-specific antibody. Because the PWM-induced anti-SRBC response by human peripheral blood B lymphocytes is a T-celldependent phenomenon (9), one would expect that the patient's $T$ cells could provide helper activity. As a matter of fact, this was the case as further demonstrated by the fact that this patient's irradiated $T$ cells provided adequate help toward PWM-stimulated antiSRBC PFC responses of normal allogeneic co-cultures. ${ }^{2}$ In this regard, we have previously reported the ability of $\mathrm{T}$ cells from CLL patients to provide helper effects in this system (22). This is somewhat at variance with previous reports of a helper T-cell defect in CLL (23). However, the latter studies were not employing the PWII-induced anti-SRBC PFC system.

In the present study, using purified serum monoclonal IgM with anti-SRBC specificity, we succeeded in raising anti-Id antibody. The anti-Id not only directly blocked the spontaneous secretion of anti-SRBC antibody by the leukemic B cells, but also blocked the PWM-induced anti-SRBC PFC responses of these cells after $6 \mathrm{~d}$ in culture. The suppression was less dramatic than that of the spontaneously secreting B cells, but it was nonetheless profound.

The mechanisms whereby this anti-Id antibody suppressed the secretion of anti-SRBC antibody by the patient's leukemic B cells is unclear at present. It is possible that the anti-Id antibody directly suppressed the function of genes that were differentiated, i.e., the

\footnotetext{
${ }^{2}$ Fauci, A. S. Unpublished observations.
} 
$V_{H}$ and $V_{L}$ genes of the CLL B cells. However, there are other alternatives that have not been completely ruled out. For example, the anti-Id antibody may have been directly cytotoxic to the CLL cells. This is unlikely, however, because the viability of the cells was not altered by the anti-Id antibody. Alternatively, the antiId antibody could have been bound to and blocked the anti-SRBC antibody in the agar after it had been secreted. This might explain the effect of the anti-Id antibody in the experiments in which the antibody was added directly to the assay system in the detection of spontaneously secreting anti-SRBC antibody on day 0 . However, it is highly unlikely in cultures stimulated with PWM and subsequently washed three times that enough anti-Id antibody could have been carried over into the assay system to interfere with the binding of antibody and thus explain the suppression by that mechanism. To directly control for this possibility, experiments were carried out in which the patient's lymphocytes were cultured for $6 \mathrm{~d}$ with PWM in the absence of the sheep anti-Id antibody. At the termination of culture, a 1:30 dilution of the anti-Id was added to culture immediately before harvesting and plaquing. The cultures were then washed three times and the cells plated for plaquing. Under these circumstances, there was no inhibition of the PFC response. Thus, although it is still conceivable that there could have been carry-over anti-Id from the original PWM-stimulated cultures that contained anti-Id into the assay system, the latter control experiment makes this highly unlikely. It is also unlikely that the anti-Id blocked the PWM receptor on the CLL lymphocyte because even the spontaneous secretion of anti-SRBC antibody was blocked by the anti-Id.

The suppression was not overcome by a powerful stimulus such as a polyclonal B-cell activator, in this case, PWM. This is of interest in that other data have indicated that tolerance induced by antigen or antibody (allotypic suppression) could be broken by polyclonal B-cell activators $(24,25)$. It should be pointed out, given the report of idiotypic determinants on T cells (26), that neither idiotypic determinants nor anti-Id activity could be demonstrated on the surface of the patient's $\mathrm{T}$ cells.

Thus, the present study has clearly demonstrated idiotypic suppression of antibody secretion by human leukemic B cells in vitro. Although the B cells studied were clearly abnormal, these findings emphasize the real and potential role of anti-Id antibodies in the immunoregulation of human B-cell function.

\section{ACKNOWEDGMENTS}

The authors wish to thank Ms. Gail Whalen and Ms. Cynthia Burch for expert technical assistance, and Ms. Gina Shankel and Mrs. Betty Sylvester for expert secretarial and editorial assistance.

\section{REFERENCES}

1. Lynch, R. E., R. J. Graff, S. Sirisimha, E. S. Simms, and H. E. Eisen. 1972. Myeloma proteins as tumor-specific transplantation antigens. Proc. Natl. Acad. Sci. U. S. A. 69: $1540-1544$.

2. Hart, D., L. Wang, L. Paulak, and A. Nisonoff. 1972. Suppression of idiotypic specificities in adult mice by administration of antiidiotypic antibodies. J. Exp. Med. 136: 1293-1300.

3. Frikke, M. J., S. H. Bridges, and R. G. Lynch. 1977. Myeloma-specific antibodies: studies of their properties and their relationship to tumor immunity. J. Immunol. 118: 2206-2212.

4. Daley, M. J., H. M. Gebel, and R. D. Lynch. 1978. Idiotype-specific transplantation resistance to MOPC315: abrogation by post-immunization thymectomy. $J$. Immunol. 120: 1620-1624.

5. Kluskens, L., and H. Kohler. 1974. Regulation of immune response by autogenous antibodies against receptor. Proc. Natl. Acad. Sci. U. S. A. 71: 5083-5087.

6. Bona, C., R. Lieberman, S. House, I. Green, and W. E. Paul. 1979. Immune response to levan. II. T independence of suppression of cross-reactive idiotypes by antiidiotypic antibodies. J. Immunol. 122: 1614-1619.

7. Nisonoff, A., S. T. Ju, and F. L. Owen. 1977. Studies of structure and immunosuppression of a cross-reactive idiotype in strain A mice. Immunol. Rev. 34: 89-117.

8. Eichmann, K., 1974. Idiotype suppression. II. Amplification of a suppressor $T$ cell with antiidiotypic activity. Eur. J. Immunol. 5: 511-517.

9. Fauci, A. S., K. R. K. Pratt, and G. Whalen. 1976. Activation of human B lymphocytes. II. Cellular interactions in the PFC response of human tonsillar and peripheral blood $\mathrm{B}$ lymphocytes to polyclonal activation by pokeweed mitogen. J. Immunol. 117: 2100-2104.

10. Fauci, A. S., and K. R. Pratt. 1976. Polyclonal activation of bone marrow-derived lymphocytes from human peripheral blood measured by a direct plaque-forming cell assay. Proc. Natl. Acad. Sci. U. S. A. 73: 3676-3679.

11. Fauci, A. S., and K. R. Pratt. 1976. Activation of human B lymphocytes. I. Direct plaque forming cell assay for the measurement of polyclonal activation and antigenic stimulation of human B lymphocytes. J. Exp. Med. 144: 674-684.

12. Avremeas, S., and T. Ternynck. 1967. Biologically active water insoluble protein polymers. I. Their use for isolation of antigens and antibodies. J. Biol. Chem. 242: 1651-1657.

13. Bona, C., and W. E. Paul. 1979. Cellular basis of regulation of expression of idiotype. I. T-suppressor cells specific for MOPC 460 idiotype regulate the expression of cells secreting anti-TNP antibodies bearing 460 idiotype. J. Exp. Med. 149: 592-600.

14. Fauci, A. S. 1975. Human bone marrow lymphocytes. I. Distribution of lymphocyte subpopulations in the bone marrow of normal individuals. J. Clin Invest. 56: 98-110.

15. Fauci, A. S. 1979. Human B cell function in a polyclonally induced plaque forming cell system. Cell triggering and immunoregulation. Immunol. Rev. 45: 93-116.

16. Preud'homme, J. L., and M. Seligmann. 1972. Surface bound immunoglobulins as a cell marker in human lymphoproliferation diseases. Blood. 40: 777-794.

17. Seligmann, M., J. L. Preud'homme, and J. C. Brouet. 1973. B and T cell markers in human proliferative blood diseases and primary immunodeficiencies, with specific reference to membrane bound immunoglobulins. Transplant Rev. 16: 85-113. 
18. Fu, S. M., R. J. Winchester, and H. G. Kunkel. 1974. Occurrence of surface IgM, IgD, and free light chains on human lymphocytes. J. Exp. Med. 139: 451-456.

19. Fu, S. M., M. Chiorazzi, H. G. Kunkel, J. P., Halper, and S. R. Harris. 1978. Induction of in vitro differentiation and immunoglobulin synthesis of human leukemic B lymphocytes. J. Exp. Med. 148: 1570-1578.

20. Fu, S. M., R. J. Winchester, T. Feizi, P. D. Walper, and H. G. Kunkel. 1974. Idiotypic specificity of surface immunoglobulin and the maturation of leukemic bone-marrow-derived lymphocytes. Proc. Natl. Acad. Sci. U. S. A. 71: 4487-4495.

21. Brouet, J. C., and A. M. Prieur. 1974. Membrane markers on chronic lymphocytic leukemia cells: a B cell leukemia with rosettes due to anti-sheep erythrocyte antibody activity of the membrane bound Ig.M and a T cell leukemia with surface Ig. Clin. Immunol. Immunopathol. 2: 481-487.

22. Fauci, A. S., K. R. Pratt, and G. Whalen. 1977. Intrinsic
B cell defect in the immunoglobulin deficiency of chronic lymphocytic leukemia. Clin Res. 25: 482A. (Äbstr.)

23. Chiorazzi, N., S. M. Fu, G. Montazeri, H. G. Kunkel, and T. Gee. 1979. T cell helper defect in patients with chronic lymphocytic leukemia. J. Immunol. 122: 10871090.

24. Bona, C., and P. A. Casanave. 1977. Release from maternally-induced allotypic suppression in rabbit by nocardia water-soluble mitogen. J. Exp. Med. 146: $881-886$.

25. Fernandez, C., L. Hammarström, G. Möller, D. Primi, and C. J. E. Smith. 1979. Immunological tolerance affects only a subpopulation of the antigen specific B lymphocytes: evidence against clonal deletion as the mechanism of tolerance induction. Immunol. Rev. 43: 3-4l.

26. Preud'homme, J. L., M. Klein, S. Labaume, and $\mathbf{M}$. Seligmann. 1977. Idiotype-bearing and antigen-binding receptors produced by blood $\mathrm{T}$ lymphocytes in a case of human myeloma. Eur. J. Immunol. 7: 840-846. 